\title{
Ethical Issues Raised by the Clinical Implementation of New Diagnostic Tools for Genetic Diseases in Children: Array Comparative Genomic Hybridization (aCGH) as a Case Study
}

\author{
Julia $\mathbf{S}^{1,2,3}$, Soulier $A^{1,2}$, Leonard $\mathbf{S}^{1,2}$, Sanlaville $\mathbf{D}^{4}$, Vigouroux $A^{3}$, Keren $\mathbf{B}^{5}$, Heron $\mathbf{D}^{5}$, Till $\mathbf{M}^{4}$, Chassaing $\mathbf{N}^{3,6}$, Bouneau $\mathbf{L}^{3}$, Bourrouillou $\mathbf{G}^{3}$, Edery $\mathbf{P}^{4}$, Calvas \\ $\mathrm{P}^{3,6}$ and Thomsen $\mathrm{AC}^{1,2}$ \\ ${ }^{1}$ UMRU 1027, Inserm, Toulouse, France \\ ${ }^{2}$ Universite de Toulouse, Universite Paul Sabatier Toulouse 3, UMR 1027, Toulouse, France \\ ${ }^{3} \mathrm{CHU}$ Toulouse, Hopital Purpan, Service de Genetique Medicale, Toulouse, France \\ ${ }^{4}$ Service de cytogenetique constitutionnelle, Hospices Civils de Lyon Inserm U1028, Lyon Neuroscience Research Center, UCBL1, TIGER team, Lyon, F-69000, France \\ ${ }^{5}$ Departement de genetique, hopital de la Pitie-Salpetriere, Assistance Publique-Hopitaux de Paris, 47-83, boulevard de l'hopital, 75013 Paris, France \\ ${ }^{6}$ Université Paul Sabatier, Equipe EA4555_GR2DE, Toulouse, France
}

Corresponding author: Julia S, Service de Genetique Medicale, Hopital Purpan, TSA 40031-31059, Cedex9, Toulouse, France, Tel: 33(0)561779055; Fax: 33(0)5 61779073; E-mail: julia.s@chu-toulouse.fr

Received date: Sep 25, 2015; Accepted date: Nov 12, 2015; Published date: Nov 18, 2015

Copyright: (2015 Julia S, et al. This is an open-access article distributed under the terms of the Creative Commons Attribution License, which permits unrestricted use, distribution, and reproduction in any medium, provided the original author and source are credited.

\begin{abstract}
High throughput genetic technologies offer the opportunity to gain precision in the diagnosis of numerous diseases and to better understand their molecular basis. However they bring new practical and ethical challenges, some of which are foreseeable and therefore amenable to the timely adoption of strategies to ensure that they are introduced and used in a just and beneficial manner. One way of foreseeing these challenges is to examine technologies that have already been transferred from research to the clinical setting in order to identify the ethical issues and develop strategies to move forward in an ethical way. One such model for new genetic technologies is Array Comparative Genomic Hybridization (aCGH), which has been gradually adopted in recent years as a standard technique in clinical genetics. CGH challenging current clinical practice regarding the detection and diagnosis of human chromosome abnormalities in intellectual disability (ID) and congenital malformations in children. Experience with aCGH has shown that it delivers an unprecedented volume of information for patients, counsellors, and health care providers but it also raises specific ethical challenges which can serve as signposts for potential issues with future, even more detailed, genetic technologies. These issues are described and illustrated through case histories, and their consequences for the patient-clinician relationship in genetic consultation are discussed. The consequences of employing this technology, as compared to the more traditional genetic diagnostic methods used in cases of intellectual disability are categorised into issues linked to 1) the vulnerable nature of patients who are mostly children, mentally retarded people or "future parents"; 2) the way in which information is controlled at each stage of the process, as a function of its potential relevance to the clinical condition being diagnosed, 3) the information related to conditions other than ID or "incidental findings" that become the rule with high throughput technologies. The issues highlighted by the clinical scenarios discussed here can be expected to occur with even greater frequency in the future as whole exome and whole genome sequencing are introduced. Building on our experience with the transfer and adoption of aCGH into clinical genetics, we have developed a grid of points to be considered when translating such technologies from research to clinic.
\end{abstract}

Keywords: Diagnostic tools; Genetic diseases

\section{Ethical Aspects of Array Comparative Genomic Hybridization (aCGH) for Intellectual Disability Diagnosis and Genetic Counselling}

\section{Introduction}

Array comparative genomic hybridization (aCGH), a method for genome-wide detection of DNA copy-number variants (CNV), was first developed in the mid 1990's as a research tool for the investigation of genomic alterations in tumours [1]. aCGH has been transferred from research to clinic in less than a decade and has become the method of choice to detect and diagnose human chromosomal constitutional abnormalities in clinical genetics departments [2].
aCGH gives a higher resolution than classic karyotyping methods and has demonstrated its scientific and medical value by uncovering new microdeletion syndromes and doubling the number of pathogenic chromosome imbalances found in symptomatic patients [3,4], used only rarely in the mid 2000's, aCGH is now considered as a first line diagnostic tool in intellectual disability, autism and multiple congenital malformation syndromes which, as molecularly highly heterogeneous genetic conditions, requiring sophisticated tools to carry out in depth explorations.

Early adopters of $\mathrm{CGH}$ in the clinical context have experienced difficulties with the interpretation and communication of results as demonstrated by the increasing numbers of clinical and technical reports in the literature [5]. The complexity of genetics generally and the general lack of familiarity with this specialised subject among patients have rendered genetic counselling discussions lengthy and 
Citation: Julia S, Soulier A, Leonard S, Sanlaville D, Vigouroux A, Keren B, Heron D, Till M, Chassaing N, Bouneau L, Bourrouillou G, Edery P, Calvas P, Thomsen AC (2015) Ethical Issues Raised by the Clinical Implementation of New Diagnostic Tools for Genetic Diseases in Children: Array Comparative Genomic Hybridization $(\mathrm{aCGH})$ as a Case Study. J Clin Res Bioeth 6: 245. doi: $10.4172 / 2155-9627.1000245$

Page 2 of 9

complex, and decisions regarding testing even more difficult. It is upon this background of already complex counselling that aCGH implications must be communicated to patients. New dimensions now need to be considered within the routine pre-test counselling sessions.

By drawing upon the experiences of French clinical genetics departments (collected via the French aCGH network), we have been able to examine the tensions between the clear utility of such technologies to extend diagnostic capabilities, and the ethical considerations specific to the patient groups most frequently receiving aCGH; namely children and adults with ID with the attendant vulnerabilities. The aim of this paper is to consider how such discussions should be approached, both in relation to pre-test decision making and in sharing of results. The ethical issues arising from typical cases and in corresponding literature have been analysed in order to contribute to the on-going discussion and production of guidelines for pan genome analyses in clinical practice [6-9].

\section{Methods}

\section{Selection of the clinical situations}

We analysed clinical situations illustrating issues of relevance coming from practice. The criteria were:

familiar situations which were being encountered with increased frequency when using CMA

situations for which there were no standard professional guidelines available to address all dimensions of the situation

unsolved problems of genetic counselling

situations which required a multidisciplinary dialogue before an approach was decided on

the reflexive and interdisciplinary approach included an ethical analysis

These criteria and the analytical method can reveal the key issues questioning practices and be used to produce proposals anchored in real cases. We thus present here 5 emblematic situations gathered from the French network on chromosomal analysis of DNA chips (Réseau d'analyse chromosomique sur puce ADN -A.C.P.A.) experience.

All cases involve affected children. CMA was offered to these patients when classical karyotyping methods had already been used without finding a genetic diagnosis. When interpreting CMA results, several cases occurred where concerns were raised regarding issues of uncertainty in the interpretation of results (case 1); detection of disease with onset later in life (case 2); and detection of carrier status (cases $3,4,5)$.

\section{Analysing the ethical dimension}

The following principles and frameworks were systematically analysed in the different cases: Respecting the autonomy of vulnerable patients, informed consent, patient/child participation, childrens rights, level of information; right to know or not to know in the case of incidental findings.

\section{Selected Clinical Situations}

The 5 following clinical situations were chosen as they illustrate questions with a important ethical component in clinical practice.

\section{Patient and family 1}

A mentally retarded 5 year old boy is referred for clinical genetics consultation; standard cytogenetic and Fragile $\mathrm{X}$ syndrome analysis are normal. aCGH analysis is carried out for both the patient and his parents and the same $2.8 \mathrm{Mb} 1 \mathrm{q} 21.1$ duplication is detected for the boy and his healthy mother. The duplication of the chromosomal region 1q21 has recently been described as a probable pathogenic rearrangement but with variable expressivity (mental retardation, psychiatric illness, cardiac anomalies) $[10,11]$. As the mother carrying a copy number variation $(\mathrm{CNV})$ in $1 \mathrm{q} 21.1$ has no specific clinical manifestations, it raises the question of the implication of the 1q21.1 $\mathrm{CNV}$ in her son's phenotype. One year later the family is seen in clinic again. The mother is pregnant and asks about the possibility of using the finding for a prenatal diagnosis. In the context of genetic counselling, the difficulty lies in evaluating the prognosis in light of our current knowledge. This case demonstrates the difficulty of interpreting anomalies whose status as pathogenic or polymorphic is still being debated in the research domain.

\section{Patient and family 2}

A patient is referred at the age of 10 years for a Clinical Genetics consultation for global developmental delay. Familial history is unremarkable. Examination shows mild craniofacial findings, macrocephaly and joint hyper laxity. High-resolution karyotype and radiological investigation are normal. aCGH is performed and leads to the detection of a $350 \mathrm{~Kb}$ deletion on chromosome 17p13.1 encompassing the tumor suppressor TP53 gene (case reported by: Schluth-Bolard et al.). Missense mutations in this gene cause LiFraumeni syndrome (LFS [MIM 151623]), a complex autosomal dominant syndrome characterized by predisposition to multiple earlyonset cancers. This case exhibits incidental findings such as copy number variants $(\mathrm{CNV})$ in genes known to be oncogenic.

\section{Patient and family $3 \& 4$}

A 13 year old boy is referred to the Genetics Department for dyspraxia and mild craniofacial findings. aCGH studies show a chromosome 2q13 deletion. This region includes the NPHP1 gene involved in Nephronophthisis (NPHP1; 256100), an autosomal recessive tubulo-interstitial nephropathy which progresses to end-stage renal failure. Homozygous deletions in NPHP1 are observed in $70 \%$ of affected children [13]. As most of NPHP1 patients also have large homozygous deletions in the $2 \mathrm{q} 13$ region, the patient could be considered as a heterozygote. Parental analysis shows that the deletion is inherited from his healthy father.

A similar situation concerns a young girl (Patient and Family 4) found to have a de novo $13 \mathrm{Mb}$ chromosome 7q31.2-q32.2 deletion encompassing the ABCC7 (CFTR) gene. These cases question the way to deal with carrier status in case of recessive diseases in families.

\section{Patient and family 5}

A young girl is referred for a clinical genetics consultation, for evaluation of mild intellectual disability. She was born at 37 weeks gestation; neonatal measurements were as follows: birth weight was $2.230 \mathrm{~kg}\left(10^{\text {th }}\right.$ centile $)$, and length was $69 \mathrm{~cm}\left(10^{\text {th }}\right.$ centile $)$. She walked at 15 months and mild intellectual disability and speech delay were noted. Familial history was unremarkable. Clinical examination shows mild craniofacial finding including microretrognathia. Standard genetic investigations are inconclusive. The results of a-CGH show a 
Citation: Julia S, Soulier A, Leonard S, Sanlaville D, Vigouroux A, Keren B, Heron D, Till M, Chassaing N, Bouneau L, Bourrouillou G, Edery P, Calvas P, Thomsen AC (2015) Ethical Issues Raised by the Clinical Implementation of New Diagnostic Tools for Genetic Diseases in Children: Array Comparative Genomic Hybridization $(\mathrm{aCGH})$ as a Case Study. J Clin Res Bioeth 6: 245. doi: $10.4172 / 2155-9627.1000245$

Page 3 of 9

Xp21.1de novo deletion of $400 \mathrm{~Kb}$ between genomic positions (BAC RP5-1145-L23 to BAC RP11-151J4) disrupting the DMD gene. This deletion was verified by FISH.

This case shows the difficulty of choosing to reveal a finding according to the best interest of the patient and/or of her family. These clinical situations illustrate three types of counselling dilemma including "uncertainty in the interpretation of the results (case 1), detection of disease with onset later in life (case 2) and detection of carrier status. What should be said to the family? How should incidental findings be dealt with.

\section{Ethical Considerations and Discussion}

The transfer of new genetic technologies from the research to the clinical setting requires rigorous evaluation, particularly in terms of analytical validity and clinical utility, as well as reflection on the ethical issues which may arise from its use [14]. These difficulties require that the transfer process is conducted with caution. The question that arises can be formulated in the following manner: how should a research instrument be converted into an effective clinical tool, and how can the set of data generated by the research process be filtered to target relevant information, bearing in mind the patient's best interests?

Through consideration of ethical issues that arose in the care of particular patients, who were all mentally retarded children, moral problems were identified and analysed. Because of the vulnerable status of these patients the discussion reflects a tension in contemporary bioethics which is caught between two conflicting visions of the patient: as an autonomous being who needs to be respected and as a vulnerable being who requires protection. This tension was the main focus of the ethical analysis performed in relation to the clinical use of aCGH.

\section{Respecting Autonomy - How to Approach Information- Giving?}

The analysis led to an examination of how to give patient information in order to facilitate informed and autonomous decisionmaking. From an ethical perspective patient information, obtaining informed consent, confidentiality and genetic counseling for individuals and families need to be addressed in an adapted way. Strategies should be put in place to improve information giving and communication during genetic counseling for aCGH in practice.

\section{The classical framework for genetic counselling - An ethos of openness and respect for autonomy}

In the vein of the autonomy-based perspective of medical ethics, genetic counselling has inherited a tradition of non-directiveness. Fraser for instance gives a definition of genetic counselling which encompasses the necessity of helping the family to make the decisions they find most appropriate and to make the best adjustment to their situation [15]. These areas of self-determination, personal adjustment and decision-making reflect the great respect in which autonomy is held. Clinical geneticists feel the need to adhere to the doctrine of autonomy and consider information as a pillar in the process of genetic counselling because this forms the basis of any decision.

However, as all the above cases show, aCGH poses challenges for the clear communication of information. In particular, trying to ensure that patients are adequately counselled for the wide variety of potential outcomes revealed with such testing is challenging. This challenge is even more pronounced in the paediatric context, as some incidental findings may relate to adult-onset conditions.

\section{Difficult results - a categorising approach}

Testing strategies which use new generation genetic technologies such as aCGH represent a paradigm shift in relation to conventional diagnostic approaches: from a hypothesis based on the phenotype, which is then explored with targeted testing, to a form of genetic screening where each deviation from the norm will be detected. This screening approach increases the risk of unexpected or incompletely validated results in comparison with the targeted approach [16]. In the past, identification of a visible chromosomal imbalance could be assumed to be the cause of a child's developmental abnormalities [17], although clinical interpretation was still challenging as not all CNVs are pathogenic or fully penetrant [18]. Common CNVs are observed in regions known to be associated with disease. Pertinent examples are the CNVs we identified at the 22q11.21 and 1q21.1 (case 1) regions and the $16 \mathrm{p} 11.2$ susceptibility locus for autism, which are present in database as normal variants, but for which clinical relevance has been well established $[19,20]$. Exploration of these zones is likely to bring doubts and uncertainty. But, as in the first case history, results obtained concerning genomic variations are not necessarily related to the observed phenotype and these alterations may be inherited from phenotypically normal parents. De novo chromosomal rearrangement in a child with ID are more likely to be pathogenic than an inherited $\mathrm{CNV}$ from a healthy parent. Moreover, as the first case illustrates, inheritance should not be considered as the only guide to pathogenicity. Some genomic variations that are inherited from a healthy parent are pathogenic and some de novo genomic variations are probably benign [21]. In the case of CNVs with incomplete penetrance that could be inherited from mildly affected or unaffected parents, as in the case 1 above (CNV at 1q21), a feeling of culpability may be generated [22], as well as the question of where the boundaries between normality and abnormality lie $[23,24]$.

As clinical interpretations clearly depend on the current state of knowledge, information from public databases such as OMIM [25], UCSC [26], Database of Genomic Variants [27], Decipher [28], Clingen [29], Pubmed [30], the database of International Standard For Cytogenomic Array (ISCA) consortium and published guideline $[31,32]$ could bring greater clarity to the biological and clinical validity of results. These should facilitate the provision of CNV results by the laboratory and assist clinicians to better understand and communicate these results. However the interpretation of such results is liable to change with evolving scientific and clinical knowledge, as the first clinical scenario above clearly illustrates. It is therefore necessary to conceive a practicable classification which integrates not only the technical and clinical validity but takes into account the clinical utility and the potential for use in genetic counselling [33,34] (as outlined in the ACCE framework [35]). It is likely that different systems of classification will be used by different centres, but they should always be explicit and clearly explained to patients prior to carrying out any tests. A classification could organise results according to their scientific reliability: from well-defined known pathogenic mutations to novel mutations of unproved pathogenicity. Another classification could rely on the presentation of the range of potential results and could propose options for what patients and families want or do not want to know, for example: (1) being informed of all findings; (2) being informed of findings for which treatments and/or prevention are available; (3) only being informed of the result if it is directly related to the presenting 
Citation: Julia S, Soulier A, Leonard S, Sanlaville D, Vigouroux A, Keren B, Heron D, Till M, Chassaing N, Bouneau L, Bourrouillou G, Edery P, Calvas P, Thomsen AC (2015) Ethical Issues Raised by the Clinical Implementation of New Diagnostic Tools for Genetic Diseases in Children: Array Comparative Genomic Hybridization $(\mathrm{aCGH})$ as a Case Study. J Clin Res Bioeth 6: 245. doi: 10.4172/2155-9627.1000245

Page 4 of 9

condition; (4) a last option could allow patients to let their physician decide which results it would be in their best interests to know.

\section{A shift of approach? How to deal with "incidental findings" that become the rule with high throughput technologies}

Incidental findings "IFs" arising in genetic context have been the source of ethical dilemmas for a long time. However, the extension of genetic exploration and in particular the recent moves towards pangenomic analysis increases the probability of unexpected information such as detecting deletions of genes involved in hereditary cancer syndromes [36,37], (Patient and Family 2) and of detecting predictive conditions such as carrier status in autosomal recessive diseases (Patient and Families 3,4) or X linked disorders (Patient and Family 5). The potential for harm resulting from IFs for genome-scan techniques has been considered in research and clinic $[38,39]$ and is the object of a never ending debate [40]. These 'secondary' results, in the pediatric context, pose specific problems and it is not clear that framework designed for the traditional model of genetic testing is optimal from an ethical point of view. Even if incidental findings following the prescription of aCGH are not a frequent outcome in routine clinical practice, their frequency and characteristics has to be further characterised [41,42], and the experience of physicians in their management have to be studied further. The disclosure of unexpected results in a clinical population is problematic because patients did not solicit them which mean that they go beyond their initial concerns. Patients may not want to hear about such results or, at least, patients may not be prepared. The strategy of disclosure and information to the family depends first on the mode of transmission of the anomaly, inherited or de novo; and second, on the clinical significance of the anomaly in terms of prediction of age of onset and severity. Whether incidental findings are communicated to patients or not is a decision incumbent upon the medical institution-the clinician and his staff or an ethical committee.

There are indeed clear guidelines about presymptomatic (adultonset condition) and carrier testing in minors which recommend that results should not be communicated to patients until their legal majority. The consensus position from various medical societies-such as the American Society of Human Genetics, the American College of Medical Genetics, the American Academy of Pediatrics and the European Society of Human Genetics (ESHG)-stipulates that predictive genetic testing of children and adolescents for adult-onset conditions and for carrier testing should be deferred where there is no immediate medical benefit $[43,44]$. In case 1 the clinical and psychological impact of the disclosure of the predictive testing for LFS in a child has to be taken in account. A decision not to reveal known results would deny them the opportunity to monitor for the early development of cancer in the future and raise questions of legal liability for a family who learns that they were not told about an identified condition. But informing the family of their risk may engender potentially unnecessary anxiety because beneficial effects in terms of prevention or treatment as a consequence of the test results have not yet been clearly demonstrated. In this situation professional guidelines discourage such testing [45].

In the same way communicating carrier or trait status to parents of heterozygote infants is of uncertain value and may cause undue anxiety (Patients and Families 3,4 and 5). On first consideration; it seems that since this kind of information has no clinical implication for individuals, it should therefore not be conveyed to parents but rather should be discussed with a young person when he or she reaches reproductive age. However even if the disclosure of such information could potentially be clinically relevant (leading to the offer of genetic counseling for the family and for further pregnancies) [46], the point is that the significance of many variants remain unclear [47]. How therefore can such information be handled in the context of knowledge that evolves so rapidly? For example it is not clear that 17p13.1 CNVs, which include TP53, are sufficient to cause LFS: none of the ten reported mentally impaired patients carrying germline $17 \mathrm{p} 13$ deletions have so far manifested cancer. Shlien, et al. [48] suggested that full deletions which encompass but do not disrupt TP53, may not cause cancer predisposition, in contrast to CNVs with at least one breakpoint within TP53.

The clinical significance of the $2 \mathrm{q} 13$ duplication is still emerging, as these copy number variations are also found in phenotypically normal and control individuals [49].

But in the context of non-targeted analysis, is it right to assume that disclosure of incidental findings should be subject to the same guidelines as predictive tests? If we consider that these "secondary results" are an integral part of such analysis, we must acknowledge that if we have a duty to respect a patient's declared right not to know, we cannot in good faith prescribe a test for them which will inevitably lead to unwanted information.

From a terminological point of view, unexpected information constitutes a new category of data that falls somewhere in between research and clinical results. The ethical aspects of genetic testing related to the use of aCGH pose the same general problems in relation to autonomy and privacy as tests which generate large scale genetic information. Several approaches have been developed in order to evaluate genetic tests in transition from research to clinical practice such as the ACCE framework for evaluation of emerging new genetic tests [50] or the "Evaluation of Genomic Applications in Practice and Prevention" (EGAPP) initiative [51]. It may be that a new approach is also needed to look at the ethical aspects of tests in transition from research to practice, evaluating whether the ethical and legal frameworks designed for the traditional model of genetic diagnosis are still accurate for next generation diagnostic procedures. The policy for disclosure of incidental findings in the context of clinical genome analysis should be clarified, ethically justified and supported by clear and easy to use procedures.

Some genetic departments restrict the proposal of large scale genome analyses to patients who would give consent (prior to testing) to be told about incidental findings. This disposition is clearly beneficial for the clinicians who would therefore not have to face dilemmas related to the disclosure of incidental findings.

Going another step further from simply dealing with such results as an unintentional consequence of a powerful diagnostic tool, the American College of Medical Genetics is calling for an active search for certain copy numbers for which a proven treatment or prevention exists, and to this end have published a list of variants fulfilling this criteria: "Recommendations for reporting incidental findings (IFs) in clinical exome and genome sequencing" [52,53]. Following these recommendations, a child and his parents undergoing "whole-genome sequencing" in the context of mental retardation would also be tested for a series of variants associated with, for example, increased risk of developing cancer, or cardiac pathologies. The working group highlighted the clinicians and laboratories "fiduciary duty to prevent harm by warning patients and their families." and concludes that "this principle supersedes concerns about autonomy," This stance, which has 
Citation: Julia S, Soulier A, Leonard S, Sanlaville D, Vigouroux A, Keren B, Heron D, Till M, Chassaing N, Bouneau L, Bourrouillou G, Edery P, Calvas P, Thomsen AC (2015) Ethical Issues Raised by the Clinical Implementation of New Diagnostic Tools for Genetic Diseases in Children: Array Comparative Genomic Hybridization $(\mathrm{aCGH})$ as a Case Study. J Clin Res Bioeth 6: 245. doi: $10.4172 / 2155-9627.1000245$

Page 5 of 9

made headlines and been the subject of intense debate, goes against international directives which advise against testing children for lateonset disorders [54].

But these views are both limiting and limited and bring into conflict two principles of medical care: the right to receive what is considered as the best health care available and the "right not to know communication tools which clarify the status of the results and let patients express their will in advance. But a future adult's wishes cannot be sufficiently known by their parents to permit a substituted judgment determination. The information thus raises a conflict of interest between the patients and their parents, and challenges the principles inspired by the doctrine of autonomy. Such reasoning is very problematic and in the case of particularly vulnerable patients, the medical staff should be especially protective.

Rethinking informed consent in terms of enhanced patient participation

Patients are being called upon to make increasingly complex decisions regarding participation in genetic testing, interpretation of results and the choice of strategies to adopt in the case of positive results, or results which are uncertain or unexpected. Should a specific form of consent be developed for these situations? The question remains open. It seems important to develop an information schema so that informed choice in this domain can be achieved. Without going as far as developing a specific model of consent, certain issues relative to informed consent which have emerged with the use of new technologies such as aCGH can be examined. Informed consent could be defined as an on-going dialogue between physician and patient during which the physician explains the issues and the patient asks questions about the risks, benefits, and probable outcomes of his possible choices and is given answers. Young children or children who lack the capacity to assent or consent should be involved as much as possible in decisions concerning their care. In practical terms, this means that medical procedures must be communicated to the patient in clear, age-appropriate language [55]. The cognitive disability of patients should not automatically prevent them from taking part in their own care related decisions. One of two perspectives is usually adopted with respect to competence to consent. The status-based approach presupposes that some patients, by virtue of their status, are necessarily incapable of making legally valid decisions about their care. Following this perspective, whole categories of patients or subpopulations (e.g., children, people with ID) may be denied the right to make their own decisions. In contrast with such an analysis, another approach, which has a more 'functional' basis, judges the issue of capacity to consent in relation to the context of a particular function or decision-making task [56]. This paper aims to promote the second approach.

Although this need for detailed information poses particular challenges when working with young patients and/or patients with intellectual difficulties, adapted counselling protocols could be developed to maximise the potential of the patient to participate in the consent process. Respect for the patient, and in particular their right to make autonomous decisions where possible requires detailed information about the uses of aCGH and the potential disadvantages (uncertainty of results, unexpected results, and 'negative' results in the face of a clinical likelihood of a genetic disorder).

The ethical framework which serves as a guide for clinicians is still evolving and requires further development to take into account the issues raised by the transfer of new technologies. And new recommendations for the return of incidental findings, announced very recently, suggest that an "opt-out" option should be offered to patients before testing. We argue that, instead of reasoning in terms of abstract/general obligations, a more practical approach is to develop sufficiently rich informed consent procedures so as to allow patient and families to fully express their preferences regarding unsolicited information and the modalities of communication of such information [57]. There is however an urgent requirement to develop a tool to improve the information given to patients and their families. Existing standards for consent forms are insufficient and need to be given the flexibility to adapt to tests and technologies in constant evolution.

These issues related to the test must be discussed with the patient and, if appropriate, their family, before they sign the consent form. The clinician has a responsibility to alert the person undergoing testing to the specific issues related to the use of new technologies. Any communication tool that is developed for use in this domain needs to be adapted to patients, and in particular should include the capacity to assist particularly vulnerable patients to participate in the consent process. They should therefore be developed in collaboration with families and piloted on a diverse range of patients affected by ID.

\section{Respecting vulnerable patient autonomy and privacy}

As highlighted by the above cases incidental findings raise a host of questions about the legitimacy of violating children's privacy by informing their parents of such findings, and about the value and appropriateness of explaining the results to children. Information about a child's carrier status for an autosomal recessive disorder only becomes relevant for the child in adult life, but it may be of great value to parents and families. The European society of human genetic stipulate that in case of testing minors, guidelines need to be established as to what unsolicited information should be disclosed in order to balance the autonomy and interests of the child and the parental rights and needs (not) to receive information that may be in the interest of their family [58].

In terms of aCGH, the conventionally adopted position does not specifically address the needs of children suffering from ID. These children may remain under guardianship: the age of majority does not have the same legal and symbolic meaning any more. Knowing that these results could be lost or they could be relevant for the parents themselves for future pregnancies, it seems that parents should be informed about such results.

However, an important question remains: does their disabled condition deprive children with intellectual disability of their right to privacy? Are they not exposed to the same psychosocial risks as others? And taking into account the variability of cognitive disability, is it even possible to predict with certainty that all these children will be incompetent forever? Definitions of ID generally contain the elements of deficient adaptive behaviour in a variety of lifespan-appropriate spheres and impaired learning skills, but the range of expression is so wide and the potential development of children so varying that guidelines considering a single status of long-term incompetence would not be adequate. Therefore, children suffering from ID deserve the same protection as other children and their right for privacy should be respected as long as there is no medical benefit to knowing their condition, and with the provision that this should be reviewed at regular intervals. 
Citation: Julia S, Soulier A, Leonard S, Sanlaville D, Vigouroux A, Keren B, Heron D, Till M, Chassaing N, Bouneau L, Bourrouillou G, Edery P, Calvas P, Thomsen AC (2015) Ethical Issues Raised by the Clinical Implementation of New Diagnostic Tools for Genetic Diseases in Children: Array Comparative Genomic Hybridization $(\mathrm{aCGH})$ as a Case Study. J Clin Res Bioeth 6: 245. doi: $10.4172 / 2155-9627.1000245$

Page 6 of 9

\section{Patient Participation: Resource Building for the Benefit of All}

aCGH, as well as other high throughput technologies in genetics, were first used in research settings and continue to be used in this context in order to build up our knowledge of the genome. These technologies have revealed, among other discoveries, that numerous apparently benign large-scale genomic variations are present in all individuals. Capable of detecting sub-microscopic gains and losses of the genome at very high resolution, aCGHs are used clinically with the goal of identifying pathogenic genomic variations that cause directly ID/congentital malformation.

Thus, aCGH is likely to generate data that are difficult to interpret in a diagnostic setting - and will likely necessitate having an analysis performed on both parents in order to help clarify the pathogenicity of variations of uncertain significance $[59,60]$ - which may be burdensome and costly for routine analysis. Should testing on the parents become a standard? This would place a burden on the laboratory, result in heavy expenses and generate anxiety for the family.

Knowledge related to genomic variations depends on the ability of contemporary science to correlate genotypes and phenotypes. That is why both benign and pathogenic genomic variations are continuously catalogued and to some extent made available in public reference databases to aid in clinical interpretation. The scale of such genetic databases increases with high throughput technologies and they have become essential tools in assessing genotype/phenotype relations. It would thus be appropriate to systematically inform patients about the general medical benefits of accepting inclusion in such databases [61]. One difficult issue associated with the use of these databases is that a systematic review of the evolving data from such databases is challenging in clinical practice: do clinicians have the ethical responsibility to re-contact families if they become aware of new clinically relevant information? Moreover, will they be able to keep abreast of relevant findings about their patients [62]? In the context of traditional genetic testing, it is generally accepted that such recontacting is desirable. However, practical considerations to operationalise such a policy and its inherent ethical complexity have prevented this from becoming a legal obligation for genetics services staff [63-65]. Guidelines need to be specifically articulated to current situations.

\section{Family counselling issues}

Ethical issues related to aCGH highlight the need to inform parents of the potential consequences of genetic results for their family. In case of recessive condition it makes sense to consider the prevalence of heterozygotes in the general population and the severity of the disease. Nephronophthisis (Patient and Family 3) is clearly less frequent than cystic fibrosis (Patient and Family 4) and in this case testing the mother would provide reassurance. Risks are thus different and genetic counselling issues in these otherwise similar situations also differ. In frequent autosomal recessive disease or for a rare disease in a highly consanguineous family genetic counselling and possibly the offer of prenatal diagnosis could be justified. Professional practical recommendations will be helpful for managing genetic counselling in these situations. Nguyen et al. [66] disuse the counselling such a finding may have various consequences for family members, including presymptomatic diagnosis of unaffected male relatives. One major issue of detection of a CNV within the dystrophin gene in a girl is the information that has to be given to the mother and the relatives [67].

The announcement of a cytogenetic abnormality with poorly known clinical consequences is particularly challenging with regard to the potential consequences on genetic counselling, carrier detection and possible prenatal diagnosis/preimplantation genetic diagnosis (PGD). The information that has to be given to parents is problematic and thus limited and dissemination of genetic information to relatives is questionable. The question here isn't that of transfer of a CGH to prenatal diagnosis - this is a further issue for debate- but the issue arises because the approach to using CNVs with incomplete penetrance or variable expression or where the pathogenicity has not been demonstrated conclusively for family genetic counselling and prenatal diagnosis has to be clarified. For CNVs where the pathogenicity has not been conclusively established, there should be clear guidelines about the level of proof required to attribute pathogenicity. Ideally functional data should be available, but this is infrequently the case. For example microdeletions and microduplications within 1q21.1 (patient and family 1) tend to be considered as pathogenic variants with incomplete penetrance; they may indeed be found in apparently healthy individuals or may be associated with congenital heart defects, developmental delay and neuropsychiatric abnormalities. The family survey is important, even with asymptomatic parents however this would raise ethical issues: anxiety of the family, testing of asymptomatic individuals (including children) and potential requests for prenatal diagnosis. This situation highlights the dilemmas experienced at the frontiers of genetic technology. It raises the question of 'at what level of certainty are we comfortable with offering prenatal diagnosis?' The ethical principles of doing good and avoiding harm are directly opposed in this situation. In seeking the benefit of identifying the cause of the patient's medical problems, a situation is created in which a little knowledge could be considered to be worse than none whatsoever.

The difficulty is to know if one should accept the request for prenatal diagnosis (and following on from this, medical termination of pregnancy) faced with an unquantifiable risk of mental retardation. Three situations may arise: (1) the CNV is known to be pathogenic; the results can be used for a future pregnancy and for testing concerned relatives. Even if the prognosis is variable this is a situation where management decisions can be based on a foundation of solid clinical knowledge; (2) the CNV is one which occurs frequently, but for which information which would allow the inference of precise risk information and solid genetic counselling is in the process of being obtained. Depending upon the amount and quality of information available, the result could potentially be used for the current pregnancy, accepting that the result is still somewhat uncertain at the present time. Such a result should not be used for other family members. A consensus position may be formed between several centres; (3) the CNV is extremely rare and so there is insufficient data to make management decisions based on solid evidence.

Parents should be supported in making an informed decision about the categories of results of which they would wish to be informed. However any such testing should be approached with caution and considered on a case by case basis. 
Citation: Julia S, Soulier A, Leonard S, Sanlaville D, Vigouroux A, Keren B, Heron D, Till M, Chassaing N, Bouneau L, Bourrouillou G, Edery P, Calvas P, Thomsen AC (2015) Ethical Issues Raised by the Clinical Implementation of New Diagnostic Tools for Genetic Diseases in Children: Array Comparative Genomic Hybridization $(\mathrm{aCGH})$ as a Case Study. J Clin Res Bioeth 6: 245. doi: $10.4172 / 2155-9627.1000245$

Page 7 of 9

\section{Proposal: Framework of Points to Review in the Translation of Genetic Technologies from Research to the Clinic}

Based upon the experience of CMA implementation in hospitalbased clinical genetics departments - where the diverse complexities which may affect the patient/clinician relationship when using CMA or large scale genome exploration high throughput technologies had not been foreseen by authorities - a grid of points to consider in the process of such translation of technical possibilities into clinical practice is proposed.

\section{Consideration of the particular characteristics of patients targeted by a specific technology}

During the process of clinical validation of innovative technologies, the impact on diagnostic strategies is evaluated according to the diseases. Ethical evaluation should also take into account vulnerabilities of potential patients. Children, mentally retarded people or "future parents" are for different reasons persons who deserve specific attention within a medical dialogue.

\section{Consideration of the flow of information at various levels the communication process}

New genetic technologies such as CMA can generate both sought for and incidental results, as well as results of uncertain reliability: filters are thus needed. The initial filters are primarily defined depending on the resolution of the technology. This is effectively what the last part of the transfer - named Clinical Utility in the ACCE framework - intends to define conceptually and to determine technically. Information is secondly filtered on its way from the laboratory to the clinics. Laboratory geneticists determine useful information depending on its description in the currently available literature and databases. Information is finally individually adapted to the patient within genetic counselling. Challenges are thus both medical and technical. CMA is already available in genetics departments but there is no database which would allow the management of the evolving interpretation of a patient's results, should further knowledge be available in the future.

\section{Consideration of the information related to "incidental findings" that become the rule with high throughput technologies}

Ethical considerations in the transfer of new genetic technologies should take into account clinicians' and patients' exposure to "incidental findings". As types of information not related to the illness being investigated are likely to be detected with increasing frequency, legal and psychological issues should be anticipated. Consent procedures should therefore be examined within the social and legal context of the country concerned in order to ensure patients are well informed about this potential outcome. Guidelines could also be prepared upstream (from transfer phases) in order to help genetic counsellors to offer adapted pre-test genetic counselling.

In French genetic departments which have adopted these technologies, the experience with CMA and its attendant complexities has indeed led to changes in consent forms or adaptations in the wording used in pre-test genetic counselling.

\section{Consideration of how to include vulnerable patients data in databases}

Clinical interpretation of genomic variations is still at the level of research; considering the amount of information generated by such tests, possible benefits for research can be derived from any such tests practiced in a defined clinical context; such research steps require that patients agree to participate in genotype-phenotype studies or databases. But clinicians involved in the care of young children with disabilities need to be aware of the ethical issues such research may involve, including the priority of the best interests of the child and the potential impact of any results where the protocol allows for return of results to participants. For the cases where the genomic variations found are related to the disease of the patients, the consent of the parents should be enough. However for the cases where the genomic variations detected have no relation with the disease of the child, the inclusion of children in a database should be discussed by an ethics committee and data should be anonymized because of the issue of future developments in the interpretations of results.

\section{Conclusion}

The experience and insights gained through the use of aCGH in clinical situations is especially valuable because the issues that have been arising share common points with issues that may be anticipated for the research-to-clinic transition of further technological developments related to high-throughput sequencing. Large-scale genome explorations change the nature of the results generated by genetic analysis, introducing new categories of risks, blurring the lines between diagnostic testing and research and challenging the classical analytical models of existing medical expertise. Existing regulations and guidelines were developed in the context of targeted testing, in line with the initial applications of genetic diagnostic technologies. In terms of adapting such regulations to the new genetic technologies, it is necessary to ask ourselves if the existing framework and good practice guidelines concerning the prescription and practice of genetic tests can be applied to the forms of genetic information generated by such technologies. In terms of developing an ethical framework, if we subscribe to the view that ethical principles are immutable and universal, it is necessary to reflect on how the autonomy of the patient can best be respected in this context, and in particular to consider how the need for the test can be reconciled with respect for the dignity and future autonomy of children. It follows that a convention specific to the needs of the pediatric population in this context, which responds to these questions and affirms the respect for the right and ability to consent of minors seems justified.

We need to take this opportunity to reflect on the current technologies and the lessons learned from these, to ensure that these technologies, as well as those being developed can be used for maximum patient benefit with minimum harm.

\section{Conflicts of Interest}

The authors declare no conflict of interest.

\section{Acknowledgement}

The authors thank the Achropuce network for their cooperation with this study. This work received funding from the European Community's Seventh Framework Programme (FP7/2007-2013) under grant agreement number 223143 (the TECHGENE project), 
Citation: Julia S, Soulier A, Leonard S, Sanlaville D, Vigouroux A, Keren B, Heron D, Till M, Chassaing N, Bouneau L, Bourrouillou G, Edery P, Calvas P, Thomsen AC (2015) Ethical Issues Raised by the Clinical Implementation of New Diagnostic Tools for Genetic Diseases in Children: Array Comparative Genomic Hybridization $(\mathrm{aCGH})$ as a Case Study. J Clin Res Bioeth 6: 245. doi: $10.4172 / 2155-9627.1000245$

Page 8 of 9

number 261123 (the GEUVADIS project) and number 200754 the GEN2PHEN project).

\section{References}

1. Rogers S, Cambrosio A (2007) Making a new technology work: the standardization and regulation of microarrays. Yale J Biol Med 80: 165-178.

2. Miller DT, Adam MP, Aradhya S, Biesecker LG, Brothman AR, et al. (2010) Consensus statement: chromosomal microarray is a first-tier clinical diagnostic test for individuals with developmental disabilities or congenital anomalies. Am J Hum Genet 86: 749-764.

3. de Vries BB, Pfundt R, Leisink M, Koolen DA, Vissers LE, et al. (2005) Diagnostic genome profiling in mental retardation. Am J Hum Genet 77: 606-616.

4. Stankiewicz P, Beaudet AL (2007) Use of array CGH in the evaluation of dysmorphology, malformations, developmental delay, and idiopathic mental retardation. Curr Opin Genet Dev 17: 182-192.

5. Ali-Khan SE, Daar AS, Shuman C, Ray PN, Scherer SW (2009) Whole Genome Scanning: Resolving Clinical Diagnosis and Management Amidst Complex Data. Pediatr Res 66: 357-363.

6. Vermeesch JR, Fiegler H, de Leeuw N, Szuhai K, Schoumans J, et al. (2007) Guidelines formolecular karyotyping in constitutional genetic diagnosis. Eur J Hum Genet 15: 1105-1114.

7. South ST, Lee C, Lamb AN, Higgins AW, Working Group for the American College of Medical Genetics and Genomics Laboratory Quality Assurance Committee (2013) ACMG Standards and Guidelines for constitutional cytogenomic microarray analysis, including postnatal and prenatal applications: Revision 2013. Genet Med 15: 901-909.

8. van El CG, Cornel MC, Borry P, Hastings RJ, Fellmann F, et al. (2013) Whole-genome sequencing in health care. European Journal of Human Genetics 21: 580-584.

9. Hehir-Kwa JY, Claustres M, Hastings RJ, van Ravenswaaij-Arts C, Christenhusz G (2015) Towards a European consensus for reporting incidental findings during clinical NGS testing. Eur J Hum Genet 23: 1601-1606.

10. Bonora M, Wieckowsk MR, Chinopoulos C, Kepp O, Kroemer G, et al. (2015) Molecular mechanisms of cell death: central implication of ATP synthase in mitochondrial permeability transition. Oncogene 34: 1608.

11. Brunetti-Pierri N, Berg JS, Scaglia F, Belmont J, Bacino CA, et al. (2008) Recurrent reciprocal 1q21.1 deletions and duplications associated with microcephaly or macrocephaly and developmental and behavioral abnormalities. Nat Genet 40: 1466-1471.

12. Mefford HC, Sharp AJ, Baker C, Itsara A, Jiang Z, et al. (2008) Recurrent rearrangements of chromosome $1 \mathrm{q} 21.1$ and variable pediatric phenotypes. N Engl J Med 359: 1685-1699.

13. Schluth-Bolard C, Sanlaville D, Labalme A, Till M, Morin I, et al. (2010) 17 p13.1 microdeletion involving the TP53 gene in a boy presenting with mental retardation but no tumor. Am J Med Genet 152: 1278-1282.

14. Saunier S, Calado J, Heilig R, Silbermann F, Benessy F, et al. (1997) A novel gene that encodes a protein with a putative src homology 3 domain is a candidate gene for familial juvenile nephronophthisis. Hum Mol Genet 6: 2317-2323.

15. Sanderson S, Zimmern R, Kroese M, Higgins J, Patch C, et al. (2005) How can the evaluation of genetic tests be enhanced? Lessons learned from the ACCE framework and evaluating genetic tests in the United Kingdom. Genet Med 7: 495-500.

16. Fraser FC (1974) Genetic counseling. Am J Hum Genet 26: 636-659.

17. Lohn Z, Adam S, Birch PH, Friedman JM (2014) Incidental findings from clinical genome-wide sequencing: a review. J Genet Couns 23: 463-473.

18. Ledbetter DH (2008) Cytogenetic technology-genotype and phenotype. N Engl J Med 359: 1728-1730.

19. Vissers LE, de Vries BB, Veltman JA (2010) Genomic microarrays in mental retardation: from copy number variation to gene, from research to diagnosis. J Med Genet 47: 289-297.
20. Hannes FD, Sharp AJ, Mefford HC, de Ravel T, Ruivenkamp CA, et al. (2009) Recurrent reciprocal deletions and duplications of 16p13.11: The deletion is a risk factor for MR/MCA while the duplication may be a rare benign variant. J Med Genet 46: 223-232.

21. Vermeesch JR, Fiegler H, de Leeuw N, Szuhai K, Schoumans J, et al. (2007) Guidelines for molecular karyotyping in constitutional genetic diagnosis. Eur J Hum Genet 15: 1105-1114.

22. Redon R, Ishikawa S, Fitch KV, Feuk L, Perry GH, et al. (2006) Global variation in copy number in the human genome. Nature 444: 444-454.

23. Houdayer F, Gargiulo M, Frischmann M, Labalme A, Decullier E, et al. (2013) The psychological impact of cryptic chromosomal abnormalities diagnosis announcement. Eur J Med Genet 56: 585-590.

24. de Ravel TJ, Balikova I, Thienpont B, Hannes F, Maas N, et al. (2006) Molecular karyotyping of patients with MCA/ MR: The blurred boundary between normal and pathogenic variation. Cytogenet Genome Res 115: 225-230.

25. Online Mendelian Inheritance in Man.

26. UCSC Genome Bioinformatics.

27. Database of Genomic Variants.

28. Decipher.

29. ClinGen.

30. Pubmed.

31. Beaudet AL (2010) Ethical issues raised by common copy number variants and single nucleotide polymorphisms of certain and uncertain significance in general medical practice. Genome Med 2: 42.

32. Shaffer LG, Bejjani BA (2006) Medical applications of array CGH and the transformation of clinical cytogenetics. Cytogenet Genome Res 115: 303-309.

33. Miller DT, Adam MP, Aradhya S, Biesecker LG, Brothman AR, et al. (2010) Consensus statement: chromosomal microarray is a first-tier clinical diagnostic test for individuals with developmental disabilities or congenital anomalies. Am J Hum Genet 86: 749-764.

34. Hayden EC (2012) Geneticists debate what to tell patients about clinical genome sequences. Nature News Blog.

35. Berg JS, Khoury MJ, Evans JP (2011) Deploying whole genome sequencing in clinical practice and public health: meeting the challenge one bin at a time. Genet Med 13: 499-504.

36. The ACCE evaluation process for genetic-testing.

37. Adams SA, Coppinger J, Saitta SC, Stroud T, Kandamurugu M, et al. (2009) Impact of genotype-first diagnosis: the detection of microdeletion and microduplication syndromes with cancer predisposition by aCGH. Genet Med 11: 314-322.

38. Pichert G, Mohammed SN, Ahn JW, Ogilvie CM, Izatt L (2011) Unexpected findings in cancer predisposition genes detected by array comparative genomic hybridisation: what are the issues? J Med Genet 48: 535-539.

39. Knoppers, BM, Joly Y, Simard J, Durocher F (2006) The emergence of an ethical duty to disclose genetic research results: International perspectives. Eur J Hum Genet 14: 1170-1178.

40. Lohn Z, Adam S, Birch PH, Friedman JM (2014) Incidental findings from clinical genome-wide sequencing: a review. J Genet Couns 23: 463-473.

41. Christenhusz GM, Devriendt K, Dierickx K (2013) To tell or not to tell? a systematic review of ethical reflections on incidental findings arising in genetics contexts. Eur J Hum Genet 21: 248-255.

42. Boone PM, Soens ZT, Campbell IM, Stankiewicz P, Cheung SW, et al. (2013) Incidental copy-number variants identified by routine genome testing in a clinical population. Genet Med 15: 45-54.

43. Boone PM, Campbell IM, Baggett BC, Soens ZT, Rao MM, et al. (2013) Deletions of recessive disease genes: $\mathrm{CNV}$ contribution to carrier states and disease-causing alleles. Genome Res 23: 1383-1394.

44. Borry P, Evers-Kiebboms G, Cornel MC, Clarke A, Public and Professional Policy Committee (PPPC) of the European Society of Human Genetics (ESHG) (2009) Genetic testing in asymptomatic minors. 
Citation: Julia S, Soulier A, Leonard S, Sanlaville D, Vigouroux A, Keren B, Heron D, Till M, Chassaing N, Bouneau L, Bourrouillou G, Edery P, Calvas P, Thomsen AC (2015) Ethical Issues Raised by the Clinical Implementation of New Diagnostic Tools for Genetic Diseases in Children: Array Comparative Genomic Hybridization $(\mathrm{aCGH})$ as a Case Study. J Clin Res Bioeth 6: 245. doi: 10.4172/2155-9627.1000245

Page 9 of 9

Background considerations towards ESHG Recommendations. Eur J Hum Genet 17: 711-719.

45. Borry P, Stultiens L, Nys H, Cassiman JJ, Dierickx K (2006) Presymptomatic and predictive genetic testing in minors: a systematic review of guidelines and position papers. Clin Genet 70: 374-381.

46. Evans DG, Lunt P, Clancy T, Eeles R (2010) Childhood predictive genetic testing for Li-Fraumeni syndrome. Fam Cancer 9: 65-69.

47. Adam MP, Justice AN, Schelley S, Kwan A, Hudgins L, et al. (2009) Clinical utility of array comparative genomic hybridization: uncovering tumor susceptibility in individuals with developmental delay. J Pediatr 154: 143-146.

48. Boone PM, Bacino CA, Shaw CA, Eng PA, Hixson PM, et al. (2010) Detection of clinically relevant exonic copy-number changes by array CGH. Hum Mutat 31: 1326-1342.

49. Shlien A, Baskin B, Achatz MI, Stavropoulos DJ, Nichols KE, et al. (2010) A common molecular mechanism underlies two phenotypically distinct 17p13.1 microdeletion syndromes. Am J Hum Genet 87: 631-642.

50. Rudd MK, Keene J, Bunke B, Kaminsky EB, Adam MP, et al. (2009) Segmental duplications mediate novel, clinically relevant chromosome rearrangements. Hum Mol Genet 18: 2957-2962.

51. Haddow JE, Palomaki GE (2004) ACCE: a model process for evaluating data on emerging genetic tests. In: Khoury MJ, Little J, Burke W (eds): Human Genome Epidemiology. Oxford University Press, New York, pp: 217-233.

52. EGAPP: Evaluation of genomic applications in practice and prevention.

53. Shkedi-Rafid S, Dheensa S, Crawford G, Fenwick A, Lucassen A (2014) Defining and managing incidental findings in genetic and genomic practice. J Med Genet 51: 715-723.

54. Green RC, Berg JS, Grody WW, Kalia SS, Korf BR, et al. (2013) ACMG recommendations for reporting of incidental findings in clinical exome and genome sequencing. Genet Med 15: 565-574.

55. Clayton EW, McCullough LB, Biesecker LG, Joffe S, Clinical Sequencing Exploratory Research Cser Consortium Pediatrics Working Group, et al. (2014) Addressing the ethical challenges in genetic testing and sequencing of children. Am J Bioeth 14: 3-9.

56. Avard DM, Knoppers BM (2002) Ethical dimensions of genetics in pediatric neurology: a look into the future. Semin Pediatr Neuro 9: 53-61.
57. Keywood K, Flynn M (2006) Healthcare decision-making by adults with learning disabilities: ongoing agendas, future challenges. Psychiatry 5: 360-362.

58. Anastasova V, Blasimme A, Julia S, Cambon-Thomsen A (2013) Genomic incidental findings: reducing the burden to be fair. Am J Bioeth 13: 52-54.

59. Van El, Martina C Cornel, Pascal Borry, Ros J Hastings, Florence Fellmann, et al. (2013) Whole-genome sequencing in health care. Recommendations of the European Society of Human Genetics. European Journal of Human Genetics 21: 580-584.

60. Rodriguez-Revenga L, Mila M, Rosenberg C, Lamb A, Lee C (2007) Structural variation in the human genome: the impact of copy number variants on clinical diagnosis. Genet Med 9: 600-606.

61. Lee C, Iafrate AJ, Brothman AR (2007) Copy number variations and clinical cytogenetic diagnosis of constitutional disorders. Nat Genet 39: S48-54.

62. Povey S, Al Aqueel AI, Cambon-Thomsen A, Dalgleish R, Den Dunnen JT, et al. (2010) Practical guidelines addressing ethical issues pertaining to the curation of human locus specific variation databases (LSDBs). Hum Mutat 31: 1179-1184.

63. Shaffer LG, Beaudet AL, Brothman AR, Hirsch B, Levy B, et al. (2007) Microarray analysis for constitutional cytogenetic abnormalities. Genet Med 9: 654-662.

64. Fitzpatrick JL, Hahn C, Costa T, Huggins MJ (1999) The duty to recontact: attitudes of genetics service providers. Am J Hum Genet 64 852-860.

65. Hunter AG, Sharpe N, Mullen M, Meschino WS (2001) Ethical, legal, and practical concerns about recontacting patients to inform them of new information: the case in medical genetics. Am J Med Genet 103: 265-276.

66. Letendre M, Godard B (2004) Expanding the physician's duty of care: a duty to recontact? Med Law 23: 531-539.

67. Brunetti-Pierri N, Berg JS, Scaglia F, Belmont J, Bacino CA, et al. (2008) Recurrent reciprocal 1q21.1 deletions and duplications associated with microcephaly or macrocephaly and developmental and behavioral abnormalities. Nat Genet 40: 1466-1471. 